\title{
The relationship between early postoperative pain and intraperitoneal residual gas after laparoscopic cholecystectomy
}

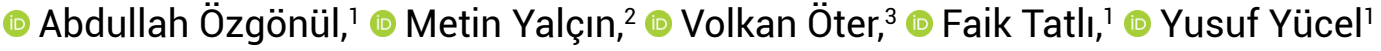 \\ 'Department of General Surgery, Harran University Faculty of Medicine, Şanlıurfa, Turkey \\ ${ }^{2}$ Department of General Surgery, Health of Science University Mehmet Akif Inan Teaching and Research Hospital, Şanlıurfa, Turkey \\ ${ }^{3}$ Department of Gastroenterological Surgery, Sakarya University Faculty of Medicine, Sakarya, Turkey
}

\begin{abstract}
Introduction: This study was designed to investigate the relationship between laparoscopic cholecystectomy (LC) patients' abdominal residual gas volume and abdominal pain in the early postoperative period, and to investigate the effect of draining the residual gas in different ways on abdominal and shoulder pain.

Materials and Methods: The study included 63 patients who were undergoing an elective LC. The patients were divided into 3 groups of equal number: a simple LC group, in which carbon dioxide was drained from the abdomen without any further treatment; an LC with aspiration group; and an LC group with a drain placed in the gallbladder bed after the procedure. Posteroanterior chest radiography was performed on all of the patients at the sixth postoperative hour to determine the amount of residual gas under the diaphragm. Postoperative shoulder and abdominal pain were evaluated using the visual analogue scale (VAS).

Results: There were no significant differences related to age, weight, sex, or surgical duration. There was a statistically significant difference at the first postoperative hour between the group that had only an LC and the LC with aspiration group when the VAS shoulder and abdominal pain scores of the 3 groups were compared. When the gas volume at the sixth hour was compared, the LC with aspiration group was found to demonstrate a significantly smaller volume than the other 2 groups $(p<0.05)$.

Conclusion: Fully aspirating the gas in the abdomen after LC will increase patient comfort by reducing back and shoulder pain commonly observed in the early postoperative period.
\end{abstract}

Keywords: Laparoscopic cholecystectomy; postoperative pain; residual gas; visual analogue scale.

\section{Introduction}

Laparoscopic cholecystectomy (LC) is superior to open cholecystectomy for a number of reasons: it causes less discomfort to the patient, reduces the length of the hospital stay, minimizes wound problems, promotes the speedy postoperative return to former activities and causes fewer postoperative pulmonary complications. ${ }^{[1,2]}$ However, disturbing abdominal and shoulder pain can be observed after laparoscopic surgery. The elimination or reduction of 
this pain may increase patient comfort, promote a quick return to normal activity and reduce pulmonary and venous system problems. ${ }^{[3,4]}$

In studies performed in the 1980s, Riedel and Semm showed radiologically that carbon dioxide $\left(\mathrm{CO}_{2}\right)$ gas remained in the peritoneal area following abdominal laparoscopy. ${ }^{[5]}$ Several studies indicate that this gas leads to irritation and shoulder pain if it remains below the diaphragm following laparoscopy. ${ }^{[6,7]}$ However, pain after laparoscopy is multifactorial and can be associated with many issues: abdominal muscle tension in the abdominal front wall caused by pneumoperitoneum (Pp); the temperature and volume of insufflated gas; anaesthetic drugs and their postoperative effects; wound size; and the use of intraperitoneal acid during the operation..$^{[8-11]}$

This study was planned to investigate the effect on LC patients' abdominal and shoulder pain of draining the residual gas through various means at an early postoperative stage.

\section{Materials and Methods}

We studied 63 patients who were scheduled for elective LC operations and who fell within the American Society of Anesthesiologists' (ASA) risk groups I, II and III. ${ }^{[12]} \mathrm{Pa}-$ tients were randomly assigned to one of the two groups consisting of 21 subjects each. The first approval from the Ethics Board of our Harran University Faculty of Medicine and informed written consents from the patients were obtained prior to the commencement of the study.

We calculated the eventual sample size according to the results of the first fifteen patients in the study. From these differences, and assuming a two-tailed $\alpha$ value of 0.05 (sensitivity 95\%) and a $\beta$ value of 0.20 (study power: $80 \%$; effect size: 0.41 ), we determined that at least 63 patients were required for our study ( $\mathrm{G}^{\star}$ Power 3 power analysis program) ${ }^{[13,14]}$ We decided to enrol at least 21 patients in each of 3 groups.

We excluded from the study patients with the following conditions: those suffering from obstructive jaundice anamnesis; those who had received a diagnosis of gallbladder cancer; those whose procedures were converted to open cholecystectomy during the surgery; and those who had additional pathologies such as bronchial asthma, chronic obstructive pulmonary disease, diabetes or hypertension.

All procedures were performed with a four-trocar entry (two $10 \mathrm{~mm}$ and two $5 \mathrm{~mm}$ ) and a standard anaesthesia protocol. At 40 minutes before surgery, midazolam was administered intramuscularly to all patients for premedication at a dose of $0.1 \mathrm{mg} \mathrm{kg}^{-1}$. Tracheal intubation was performed 3 minutes after anaesthesia induction, with 1 $\mathrm{mg} \mathrm{kg}{ }^{-1}$ remifentanil, $2 \mathrm{mg} \mathrm{kg}^{-1}$ propofol and $0.1 \mathrm{mg} \mathrm{kg}^{-1}$ vecuronium being administered to all patients. After intubation, anaesthesia maintenance was provided by an infusion of 5-8\% desflurane, $3 \mathrm{~L} / \mathrm{min}$ air, $2 \mathrm{~L} / \mathrm{min}_{2}$ and 0.25 $\mathrm{mg} / \mathrm{kg} / \mathrm{min}$ remifentanil. The insulated gas temperature was $21^{\circ} \mathrm{C}$ in our study.

The patients were divided in three group in our study, in the LC group (Group I), CO2 was completely drained from the abdomen without any treatment after the laparoscopy. In the LCD group (Group II), a drain was placed in the gallbladder bed after the procedure. In the LCA group (Group III), an aspirator was used to remove the gas under the diaphragm following the procedure.

Posteroanterior (PA) chest radiographs were taken for all patients at the 6th postoperative hour, and the height and length of the gas bubbles under the right diaphragm were measured in order to calculate the gas volumes, as follows:

Volume $=2 \pi r^{3} / 3+\pi z^{3} / 3-\pi r^{2} z$

where

$\mathrm{X}=$ height of gas bubbles

$\mathrm{y}=$ length of $\operatorname{arc} / 2$

$\mathrm{r}=\mathrm{x} 2+\mathrm{y} 2 / 2 \mathrm{y}$

$z=r-y(3)$

Patients' postoperative pain was evaluated using a visual analogue scale (VAS) at the $1^{\text {st }}, 4^{\text {th }}$ and $12^{\text {th }}$ postoperative hours by a surgical nurse who was unaware of the group to which each patient belonged. Pain severity was assessed from 0 (no pain) to 10 (unbearable pain intensity). Daily analgesic requirements were calculated in terms of consumption per day (Diclofenac sodium/bulb, $75 \mathrm{mg} /$ amp). Analgesics were administered to patients whose VAS score was more than 5 .

\section{Statistical Analysis}

All analyses were performed using the Statistical Package for the Social Sciences (SPSS) for Windows, version 16.0 (SPSS, Chicago, Ill., USA). All data were expressed as means and standard deviations. The distribution of the data was tested using the Kolmogorov-Smirnov test. 
One-way analysis of variance (ANOVA) testing was used for comparisons between groups, and the Bonferroni correction was used as a post-hoc test. Pearson's correlation test was used to assess relations between parameters. A $p$ value $<0.05$ was considered statistically significant.

\section{Results}

There were no significant differences between the groups in terms of age, body mass index (BMI), gender, duration of surgery or volume of gas (Table 1).
There was a significant difference at the first postoperative hour when shoulder and abdominal pain were compared for all three groups using VAS scores; specifically, there was a significant difference between the LC and LCA groups for both shoulder and abdominal pain ( $\mathrm{p}=0.022$ and 0.03$)$.

There were no significant differences between the groups in terms of shoulder and abdominal pain at the $4^{\text {th }}$ and $12^{\text {th }}$ postoperative hours.

A significant positive correlation was found between the groups in terms of shoulder and abdominal pain at the $1^{\text {st }}$

\begin{tabular}{|c|c|c|c|c|}
\hline & LC & LCD & LCA & $\mathbf{p}^{*}$ \\
\hline & Mean $\pm S D$ & Mean士SD & Mean士SD & \\
\hline >Age (years) & $40 \pm 14$ & $36 \pm 11$ & $36 \pm 12$ & 0.579 \\
\hline Sex (female/male) & $1.28 \pm 0.46$ & $1.23 \pm 0.43$ & $1.33 \pm 0.48$ & 0.800 \\
\hline Body mass index & $30 \pm 4$ & $31 \pm 5$ & $32 \pm 5$ & 1.000 \\
\hline Operation time (minute) & $38 \pm 10$ & $38 \pm 9$ & $39 \pm 11$ & 0.897 \\
\hline Used $\mathrm{CO}_{2}(\mathrm{~L})$ & $28 \pm 8$ & $33 \pm 7$ & $31 \pm 5$ & 0.913 \\
\hline
\end{tabular}

*Annova test. LC: Laparoscopic cholecystectomy; SD: Standart deviation; LCD: Laparoscopic cholecystectomy + drainage; LCA: Laparoscopic cholecystectomy + aspiration; ( $<0.05$ is significant).

\section{Table 2. Comparison of shoulder pain levels between two groups}

\begin{tabular}{|c|c|c|c|c|}
\hline & $\frac{\text { LC }}{\text { Mean } \pm S D}$ & $\frac{\text { LCD }}{\text { Mean } \pm S D}$ & $\frac{\text { LCA }}{\text { Mean } \pm S D}$ & $\mathbf{p}^{*}$ \\
\hline $1^{\text {th }}$ hour & $5.47 \pm 1.74$ & $4.38 \pm 1.96$ & $3.80 \pm 2.11$ & $0.024^{a}$ \\
\hline $4^{\text {th }}$ hour & $4.14 \pm 1.06$ & $3.85 \pm 1.85$ & $4.04 \pm 2.01$ & 0.857 \\
\hline $12^{\text {th }}$ hour & $3.42 \pm 1.66$ & $3.66 \pm 2.22$ & $3.52 \pm 2.56$ & 0.939 \\
\hline
\end{tabular}

"Annova test. aSignificance of LCA group compared with LC group $(p=0.024)$. LC: Laparoscopic cholecystectomy; SD: Standart deviation; LCD: Laparoscopic cholecystectomy + drainage; LCA: Laparoscopic cholecystectomy + aspiration.

\section{Table 3. Comparison of abdominal pain levels between two groups}

\begin{tabular}{|c|c|c|c|c|}
\hline & LC & LCD & LCA & $\mathbf{p}^{*}$ \\
\hline & Mean $\pm S D$ & Mean $\pm S D$ & Mean $\pm S D$ & \\
\hline $1^{\text {th }}$ hour & $5.42 \pm 2.18$ & $4.28 \pm 2.05$ & $3.66 \pm 2.19$ & $0.032^{\circ}$ \\
\hline $4^{\text {th }}$ hour & $3.57 \pm 1.93$ & $3.42 \pm 1.56$ & $4.04 \pm 1.98$ & 0.525 \\
\hline $12^{\text {th }}$ hour & $3.52 \pm 1.60$ & $3.95 \pm 0.80$ & $3.66 \pm 2.39$ & 0.716 \\
\hline
\end{tabular}

"Annova test. aSignificance of LCA group compared with LC group $(p=0.032)$. LC: Laparoscopic cholecystectomy; SD: Standart deviation; LCD: Laparoscopic cholecystectomy + drainage; LCA: Laparoscopic cholecystectomy + aspiration. 


\section{Table 4. Bubble dimensions}

\begin{tabular}{|c|c|c|c|c|}
\hline \multirow[t]{2}{*}{ Gas Volume } & LC & LCD & $\operatorname{LCA}^{x}$ & $\mathbf{p}^{*}$ \\
\hline & Mean $\pm S D$ & Mean $\pm S D$ & MeanะSD & \\
\hline Height (cm) & $0.5(0-1.2)$ & $0.8(0-1.5)$ & $0.8(0-1.4)$ & 0.001 \\
\hline Length (cm) & $6.2(0-13)$ & $9.1(0-15)$ & $7.50-14)$ & 0.001 \\
\hline Volume (ml) & $10.2(0-22)$ & $29.8(0-65)$ & $28(0-62)$ & 0.001 \\
\hline
\end{tabular}

and $4^{\text {th }}$ postoperative hours.

Gas volumes under the diaphragm in the LCA group were statistically low compared with those of the other two groups as measured using chest radiographies at the $6^{\text {th }}$ postoperative hour ( $\mathrm{p}=0.01$, Table 4$)$.

\section{Discussion}

Abdominal pain is one of the most common problems in patients undergoing abdominal surgery. Although this issue continues to be reduced through the development of laparoscopic surgery, it remains unresolved..$^{[3,4]}$

Studies show that less pain development is observed after LC than after open cholecystectomy. However, it is reported in numerous studies that abdominal and shoulder pain are common after LC. Some of the causes of pain reported in these studies include tension of the abdominal muscles, hypothermic gas and pressure on the abdominal wall created by $\mathrm{Pp}$, as well as the quantity and type of gas. As well, residual gas remaining under the diaphragm after Pp has been cited as being responsible for the back and shoulder pain observed in the postoperative period. ${ }^{[15,16]}$ According to other studies, the accumulation of $\mathrm{CO}_{2}$ gas under the diaphragm causes pain both by itself and when combined with water, which produces carbonic acid and causes irritation to the phrenic nerve. ${ }^{[1718]}$ A significant reduction has been identified in the incidence of postoperative shoulder pain following LC when gas is removed from the abdominal cavity ${ }^{[18]}$ This suggests to us that, whether the pain is formed by stimulating the nerve endings in the diaphragm or by stretching the diaphragm and abdominal wall, the complete removal of gas will provide an effective analgesia in patients treated with LC. ${ }^{[3,4]}$ The abdominal and shoulder pain are compared in our study and the only statistically significant difference we found when comparing all three groups was that between the
LCA and LC groups at the first postoperative hour, with the VAS scores indicating shoulder and abdominal pain reduction in the LCA group (Table 2 and 3). These results support our theory.

Our objective in placing a drain in the gallbladder area in the LCD group was to drain the accumulated fluid after LC. However, it had the additional effect of reducing the remaining air in the abdomen. As noted above, some studies in the literature have reported that discharging the residual gas under the diaphragm by means of a drain was found to reduce postoperative pain. However, other studies have reported that using the drain had no effect on postoperative pain. ${ }^{[18-20]}$ The fact that different results were obtained by using drains may be interpreted to indicate that the drain is not effective in discharging the residual gas. In our study, as well, there were no statistically significant differences between the VAS scores of the LCD group and those of the other groups in our study.

It was concluded that, as well as the use of non-steroidal anti-inflammatory drugs, the full evacuation of intraperitoneal gas at the end of the operation is necessary for analgesia following LC. Further studies are necessary to reduce pain in the postoperative period and to evaluate the pain mechanism.

\section{Disclosures}

Ethichs Committee Approval: The study was approved by the Local Ethics Committee.

Peer-review: Externally peer-reviewed.

Conflict of Interest: None declared.

\section{References}

1. Yoshida T, Kobayashi E, Suminaga $Y$, Yamauchi H, Kai T, Toyama N, et al. Hormone-cytokine response. Pneumoperi- 
toneum vs abdominal wall-lifting in laparoscopic cholecystectomy. Surg Endosc 1997;11:907-10. [CrossRef]

2. Ortega $A E$, Peters $\mathrm{JH}$, Incarbone R, Estrada L, Ehsan A, Kwan $Y$, et al. A prospective randomized comparison of the metabolic and stress hormonal responses of laparoscopic and open cholecystectomy. J Am Coll Surg 1996;183:249-56.

3. Kafali H, Karaoglanoglu M, Oksuzler C, Bozkurt S. Active intraperitoneal gas aspiration to reduce postoperative shoulder pain after laparoscopy. The Pain Clinic 2013;16:97-200.

4. Wills VL, Hunt DR. Pain after laparoscopic cholecystectomy. Br J Surg 2000;87:273-84. [CrossRef]

5. Riedel HH, Semm K. The post-laparoscopic pain syndrome (author's syndrome) [Article in German]. Geburtshilfe Frauenheilkd 1980;40:635-43.

6. Puttick MI, Scott-Coombes DM, Dye J, Nduka CC, MenziesGow NM, Mansfield AO, et al. Comparison of immunologic and physiologic effects of $\mathrm{CO} 2$ pneumoperitoneum at room and body temperatures. Surg Endosc 1999;13:572-5. [CrossRef]

7. Jacobs VR, Morrison JE Jr. Warmed insufflation carbon dioxide gas for laparoscopic cholecystectomy. Surg Endosc 2001;15:1244-5. [CrossRef]

8. Jacobs VR, Morrison JE Jr, Mettler L, Mundhenke C, Jonat W. Measurement of $\mathrm{CO}(2)$ hypothermia during laparoscopy and pelviscopy: how cold it gets and how to prevent it. J Am Assoc Gynecol Laparosc 1999;6:289-95. [CrossRef]

9. Nguyen NT, Furdui G, Fleming NW, Lee SJ, Goldman CD, Singh $A$, et al. Effect of heated and humidified carbon dioxide gas on core temperature and postoperative pain: a randomized trial. Surg Endosc 2002;16:1050-4. [CrossRef]

10. Fredman B, Jedeikin R, Olsfanger D, Flor P, Gruzman A. Residual pneumoperitoneum: a cause of postoperative pain after laparoscopic cholecystectomy. Anesth Analg 1994;79:1524. [CrossRef]

11. Korell M, Schmaus F, Strowitzki T, Schneeweiss SG, Hepp H. Pain intensity following laparoscopy. Surg Laparosc Endosc 1996;6:375-9. [CrossRef]
12. Menke H, John KD, Klein A, Lorenz W, Junginger T. Preoperative risk assessment with the ASA classification. A prospective study of morbidity and mortality in various ASA classes in 2,937 patients in general surgery [Article in German]. Chirurg 1992;63:1029-34.

13. Faul F, Erdfelder E, Lang AG, Buchner A. G*Power 3: a flexible statistical power analysis program for the social, behavioral, and biomedical sciences. Behav Res Methods 2007;39:17591. [CrossRef]

14. Incebiyik A, Vural $M$, Camuzcuoglu $H$, Taskin A, Camuzcuoglu A, Hilali NG, et al. Can circulating M30 and M65 levels be beneficial markers in the diagnosis and management of patients with complete hydatidiform mole? Wien Klin Wochenschr 2016;128:566-71. [CrossRef]

15. Avtan L. Penumoperitoneum. End-Lap. ve Minimal İnvaziv Cerrahi Derg 1995;2:81-6.

16. Farley DR, Greenlee SM, Larson DR, Harrington JR. Doubleblind, prospective, randomized study of warmed, humidified carbon dioxide insufflation vs standard carbon dioxide for patients undergoing laparoscopic cholecystectomy. Arch Surg 2004;139:739-43. [CrossRef]

17. Jakeways MS, Mitchell V, Hashim IA, Chadwick SJ, Shenkin A, Green CJ, et al. Metabolic and inflammatory responses after open or laparoscopic cholecystectomy. $\mathrm{Br} \mathrm{J}$ Surg 1994;81:127-31. [CrossRef]

18. Koc M, Ertan T, Tez M, Kocpinar MA, Kilic M, Gocmen E, et al. Randomized, prospective comparison of postoperative pain in low- versus high-pressure pneumoperitoneum. ANZ J Surg 2005;75:693-6. [CrossRef]

19. Nursal TZ, Yildirim S, Tarim A, Noyan T, Poyraz P, Tuna N, et al. Effect of drainage on postoperative nausea, vomiting, and pain after laparoscopic cholecystectomy. Langenbecks Arch Surg 2003;388:95-100.

20. Shamim M. Routine sub-hepatic drainage versus no drainage after laparoscopic cholecystectomy: open, randomized, clinical trial. Indian J Surg 2013;75:22-7. [CrossRef] 